\title{
Plume generation in natural thermal convection at high Rayleigh and Prandtl numbers
}

\author{
By C. LITHGOW-BERTELLONI ${ }^{1}$, M. A. RICHARDS ${ }^{2}$, \\ C. P. CONRA D ${ }^{3}$ AND R. W. GRIFFITHS \\ ${ }^{1}$ Department of Geological Sciences, University of Michigan, Ann Arbor, MI 48109, USA \\ ${ }^{2}$ Department of Earth and Planetary Science, University of California, Berkeley, \\ CA 94720, USA \\ ${ }^{3}$ Seismological Laboratory, California Institute of Technology, Pasadena, CA 91125, USA \\ ${ }^{4}$ Research School of Earth Sciences, The Australian National University, G.P.O. Box 4, \\ Canberra A.C.T. 0200, Australia
}

(Received 14 January 1999 and in revised form 2 October 2000)

We study natural thermal convection of a fluid (corn syrup) with a large Prandtl number $\left(10^{3}-10^{7}\right)$ and temperature-dependent viscosity. The experimental tank $(1 \times$ $1 \times 0.3 \mathrm{~m}$ ) is heated from below with insulating top and side boundaries, so that the fluid experiences secular heating as experiments proceed. This setup allows a focused study of thermal plumes from the bottom boundary layer over a range of Rayleigh numbers relevant to convective plumes in the deep interior of the Earth's mantle. The effective value of $R a$, based on the viscosity of the fluid at the interior temperature, varies from $10^{5}$ at the beginning to almost $10^{8}$ toward the end of the experiments. Thermals (plumes) from the lower boundary layer are trailed by continuous conduits with long residence times. Plumes dominate flow in the tank, although there is a weaker large-scale circulation induced by material cooling at the imperfectly insulating top and sidewalls. At large $R a$ convection is extremely time-dependent and exhibits episodic bursts of plumes, separated by periods of quiescence. This bursting behaviour probably results from the inability of the structure of the thermal boundary layer and its instabilities to keep pace with the rate of secular change in the value of $R a$. The frequency of plumes increases and their size decreases with increasing $R a$, and we characterize these changes via in situ thermocouple measurements, shadowgraph videos, and videos of liquid crystal films recorded during several experiments. A scaling analysis predicts observed changes in plume head and tail radii with increasing $R a$. Since inertial effects are largely absent no transition to 'hard' thermal turbulence is observed, in contrast to a previous conclusion from numerical calculations at similar Rayleigh numbers. We suggest that bursting behaviour similar to that observed may occur in the Earth's mantle as it undergoes secular cooling on the billion-year time scale.

\section{Introduction}

Solid-state thermal convection in the Earth's mantle is reflected in surface plate motions, or plate tectonics. The effective Prandtl number $P r$ for mantle convection is virtually infinite, because the average viscosity of the mantle is of order $10^{21} \mathrm{~Pa} \mathrm{~s}$ (Haskell 1935). However, due to the large depth of the mantle $(3000 \mathrm{~km})$, the effective 
Rayleigh number $R a$ for mantle convection is thought to be of order $10^{7}-10^{9}$. Understanding mantle convection is one of the principal goals of research in geodynamics, but, besides this study and one other investigation (Weeraratne \& Manga 1998), very few laboratory experiments have been performed at such large $R a$ while maintaining large $\operatorname{Pr}$ (Goldstein, Chiang \& See 1990).

Mantle convection related to plate tectonics and driven by surface cooling is strongly controlled by the extreme rheological contrasts represented by the platemantle system (e.g. Davies \& Richards 1992), and is not very amenable to study with laboratory fluid models. Some recent experiments with molten waxes have tried to reproduce some aspects of plate behaviour (rifting) but not the entire platemantle convective system (e.g. Ragnarsson et al. 1996). However, a second mode of mantle convection is also present in the form of hot, low-viscosity upwelling plumes that are thought to be the underlying cause of such volcanic 'hotspots' as Hawaii, Iceland, and Yellowstone (Morgan 1972, 1981). These plumes probably result from a thermal boundary layer at the bottom of the mantle that forms in response to the flow of heat out of the core. Initial plume 'heads' are thought to be responsible for enormous flood basalt eruptions (Morgan 1981; Richards, Duncan \& Courtillot 1989; Richards et al. 1991; Griffiths \& Campbell 1990), such as the Deccan and Siberian Traps, that may play an important role in mass extinction events in the Earth's history (Renne et al. 1995). Volcanic chains such as the Hawaiian islands are formed subsequently as a tectonic plate moves over the conduit established by the plume tail. Thus understanding the dynamics of both initial plume 'heads' and remaining plume conduits, or 'tails', remains an important problem of geodynamics, which can be investigated in laboratory-scale studies using viscous oils or syrups.

Laboratory models of convection published so far do not reproduce the plate tectonic mode of mantle convection, so it is not possible at the present time to represent both the plate and plume modes of convection in laboratory experiments. However, the geological record of major hotspot plumes, such as Hawaii, Iceland, and Yellowstone, suggest that the plume mode may be relatively unaffected by the plate mode until plumes actually impinge on the overlying plates. (This may not be true at large lengthscales, or in the stochastic sense, as plate-related flow may modulate the occurrence of plume clusters (e.g. Richards, Hager \& Sleep 1988; Weinstein \& Olson 1990; Steinberger \& O'Connell, 1998), but it certainly may hold for individual plumes.) Referring to the most conspicuous example, the chain of islands and seamounts due to the Hawaiian-Emperor plume appear to trace out plate motion over the plume, while there appears to be little or no appreciable horizontal deflection of the plume (Richards \& Griffiths 1988; Griffiths \& Richards 1989). From the fluid mechanical perspective, this observation is perplexing, even bizarre, and implies clearly that the upper and lower boundary layers of mantle convection are only very weakly coupled, probably due to a zone of very low viscosity immediately beneath the plates. Indeed, the independence of the plate and plume modes has remained an underlying tenet of most theories of hotspot volcanism dating from the original hypotheses of Wilson (1963) and Morgan (1972, 1981).

So far, experimental studies of mantle plumes have been of two main types. In the first, plumes are created artificially by injection of buoyant material into an overlying fluid, and their subsequent development is followed (e.g. Olson \& Singer 1985; Richards \& Griffiths 1988; Feighner \& Richards 1995; Griffiths 1986; Griffiths \& Campbell 1990). These experiments are somewhat unsatisfactory in that they do not address at all the boundary layer instabilities that give rise to plumes.

The second major category of experiments flow of the more classical Rayleigh- 
Bénard type, in which a fluid is heated from below and cooled from above by isothermal baths, and both upwelling and downwelling plumes form from the lower and upper boundary layers. Experiments by White (1988) built substantially on the earlier results of Busse \& Whitehead (1971), treating temperature-dependent viscosity (in Lyle's Golden Syrup) but achieving only a modest $R a$ of $\sim 10^{5}$, so that steady, closed cells formed. Such experiments probably have little relevance to the plume mode of mantle convection. Davaille \& Jaupart (1993) achieved higher $R a\left(\sim 10^{6-8}\right)$ with large viscosity contrasts using corn syrup in a similar setup, and Olson et al. (1988) carried out experiments to investigate interactions between plumes and the overlying boundary layer or lithosphere, again in the bottom-heated, top-cooled arrangement. However, such experiments do not reproduce the plate mode of convection associated with Earth's cooling upper boundary layer, and instead yield either a frozen (high viscosity contrast case) or continuously mobile (un-platelike) upper boundary layer. More importantly, none of these experiments exhibits upwelling plumes that appear in any substantial way independent of the motions of, and heat transfer through, the upper boundary layer. Our inability to simulate in the laboratory the effects of a pronounced low-viscosity zone beneath Earth's lithosphere inhibits further study of this decoupling phenomenon.

In this paper we describe experiments conducted on mantle plumes with bottom heating and top insulation, so that only the action of the bottom boundary layer is significant. This allows us to concentrate on processes of plume instability and evolution, which may, in the Earth, occur similarly in isolation from the action of the upper boundary layer. Of course, the applicability of such an approach remains arguable until we know more, observationally, about plumes in Earth's mantle. However, we believe that this end-member approach is at least as likely to be relevant to the formation and dynamics of mantle plumes as the top-cooled experiments, and hence constitutes a new and useful approach to the problem. Unfortunately, our results end up being rather difficult to compare to the more classical studies, as those studies all involve very strong upper and lower boundary layer interactions, and usually stable, closed cells that are probably irrelevant to the mantle plume phenomenon.

We have used corn syrup in a large tank, heated from below and insulated at the top and sides, to study plume formation at $R a$ up to $10^{8}$ while maintaining high $P r$. This combination of experimental conditions is unique as far as we know, and yields qualitatively new behaviour. We have analysed the stability of plumes, their dimensions, and the relative sizes of plume heads and tails for a wide range of $R a$ relevant to Earth's mantle. Our experiments reveal, somewhat serendipitously, several examples of bursting episodes in plume-dominated convection which probably result from secular heating of the tank of fluid, and the consequent secular decrease of the fluid viscosity and increase in $R a$. The history of the Earth is most similar to one of secular cooling rather than heating. However, such mode transitions may also occur in experiments in which there is secular cooling rather than heating.

\section{Experimental setup}

\subsection{Design considerations}

For high Prandtl number fluids the size of the tank is critical for achieving high $R a$. Our tank had a height of $30 \mathrm{~cm}$ and an aspect ratio of $3: 1$. The aspect ratio was chosen to minimize the effects of the sidewalls on the flow while maintaining a 
practical tank size and allowing for shadowgraph visualization from the side: large $R a$ could be achieved with a fluid of lower viscosity in a shallower tank, but large $\mathrm{Pr}$ would not be maintained. The top boundary condition for the Earth's mantlelithosphere system is isothermal and, at least under the present dynamical regime, the lithospheric plates represent the cold unstable upper boundary. However, simulating strong Earth-like plates at the top surface is not experimentally feasible, and a simple temperature dependence of viscosity at a cooled upper boundary is arguably not a good model and does not give rise to widely spaced descending slabs (e.g. Olson et al. 1988). We chose instead an insulating boundary condition, which approximates the conditions experienced by rapidly ascending plumes before they feel the effects of the near surface, or lithosphere. Thus we were not attempting to investigate the interactions between plate and plume convection modes. With this boundary condition we were also able to fully visualize the planform of convection, as explained below. Similarly, for the sidewalls we sacrificed insulation to enhance visualization.

In the Earth's mantle the bottom thermal boundary layer, at the core-mantle boundary, lies on a free-slip surface, the liquid outer core. In our experiments the bottom is a no-slip boundary. Simulation of a free-slip boundary in the laboratory would require a second basal fluid of high density and extremely low viscosity, relative to the corn syrup, a system which has other difficulties and limitations in the laboratory. The bottom boundary condition was isothermal (as in the Earth), which is easy to maintain with a hot water bath beneath a thin aluminium plate. Heating of the tank is sufficiently slow that the experiments are in quasi-steady state, although complete secular equilibrium is not realized, as discussed below. This arrangement allows us to pass through a wide range of Rayleigh numbers in a single run, while maintaining a focus on bottom boundary layer instabilities.

Corn syrup has a fairly strong temperature dependence of viscosity (approximately exponential), which is important in the initial phases of our experiments. However, in the latter phases where larger $R a$ is achieved, the maximum viscosity contrast at any given time is reduced to only a factor of 2 or 3 , due to the reduced temperature difference between the bottom temperature bath and the interior of the tank.

Thick Plexiglas side and top walls allowed full visualization of the planform of convection and of the vertical structure of the flow for the entire run. With a thermocouple array inside the tank we measured internal temperature fluctuations as well as heat losses through the top and side boundaries.

\subsection{Apparatus and working fluids}

Experiments were performed in a Plexiglas tank with dimensions $1 \times 1 \times 0.3 \mathrm{~m}$ deep, giving $\sim 3 \times 1$ aspect ratio (figure 1). The sidewalls were $2.4 \mathrm{~cm}$ in thickness. The working fluid in the tank was in direct contact with a sheet of glass at the top, $0.635 \mathrm{~cm}$ thick (because the tank was designed to allow for top cooling in other experiments). Above the glass sheet a layer of air $(2.5 \mathrm{~cm}$ height $)$ was enclosed by bolting a sheet of Plexiglas $(1.1 \mathrm{~cm}$ thick) to the sidewalls. This ensured the structural integrity of the tank during the experiments by reducing flexure of the sidewalls. The Plexiglas plate and air gap ensured good thermal insulation.

The bottom of the tank consisted of a sheet of aluminium $0.635 \mathrm{~cm}$ thick. The entire tank rested on a stainless steel water tank, which served as the heating element for the experiments. The water tank (height $10 \mathrm{~cm}$ ) contained an internal circulation system to ensure even heating of the aluminium sheet. The sides and bottom of the water tank were insulated with a wooden support base. The sides of the Plexiglas tank were not insulated allowing full imaging of the flow. Water was pumped from a 


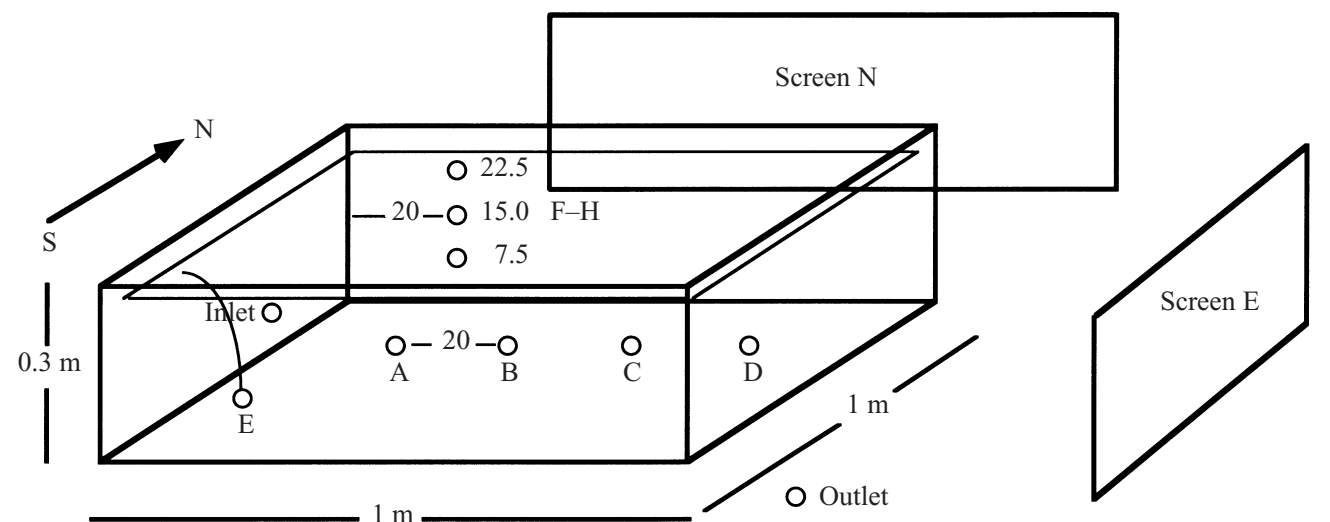

FIGURE 1. Sketch of the tank indicating dimension and placement of thermocouples A-H. Thermocouples A-D were inserted from the bottom of the tank and spaced $20 \mathrm{~cm}$ apart and $20 \mathrm{~cm}$ from the closest sidewall. Thermocouple $\mathrm{E}$ was bent and inserted from the west sidewall. Its tip was $20 \mathrm{~cm}$ from the wall and $2 \mathrm{~cm}$ above the bottom. The heights of $\mathrm{A}$ and $\mathrm{B}$ were $2 \mathrm{~cm}$ from the bottom, C $14.5 \mathrm{~cm}$ and $\mathrm{D} 1 \mathrm{~cm}$. Three thermocouple pairs located along the inner and outer north sidewall $(\mathrm{F}-\mathrm{H})$ were spaced $7.5 \mathrm{~cm}$ apart in the vertical direction and $20 \mathrm{~cm}$ away from the closest junction to another sidewall. Thermocouple I was at the water inlet hose and thermocouple $J$ at the water outlet. Probe K was located at the top of the glass, $10 \mathrm{~cm}$ from the south sidewall. Probe $\mathrm{L}$ sat on top of the Plexiglas cover, also $10 \mathrm{~cm}$ from the south sidewall. Shadowgraph screens were positioned $50 \mathrm{~cm}$ from the tank behind the north sidewall (screen $\mathrm{N}$ ) and behind the east wall (screen E). The arrow and the letters $\mathrm{S}$ and $\mathrm{N}$ indicate the geographic orientation of the tank used to indicate the direction of the large-scale circulation described in the text.

\begin{tabular}{clc}
\hline Property & \multicolumn{1}{c}{ Value at $25^{\circ} \mathrm{C}$} & \multicolumn{1}{c}{ Temperature-dependence } \\
$\eta$ & $43 \mathrm{~Pa} \mathrm{~s}$ & $\eta(T)=\exp \left(A+B T+C T^{2}\right)$ \\
$\rho$ & $1428 \mathrm{~kg} \mathrm{~m}^{-3}$ & $\rho(T)=\exp \left(D+E T+F T^{2}\right)$ \\
$\alpha$ & $1.4 \times 10^{-4}$ & $\alpha(T)=E+F T$ \\
$k$ & $0.358 \mathrm{~W} \mathrm{~m}^{-1} \mathrm{~K}^{-1}$ & \\
$C_{p}$ & $2.3 \mathrm{~J} \mathrm{~kg}^{-1} \mathrm{~K}^{-1}$ & \\
$\kappa$ & $1.1 \times 10^{-7} \mathrm{~m}^{2} \mathrm{~s}^{-1}$ & \\
TABLE 1. Material properties for corn sweetener ADM $62 / 43 . \eta$ and $\rho$ were measured in the labora- \\
tory. $k, C_{p}$ were provided by ADM. $A=7.72 ; B=-0.18 ; C=0.00087 ; D=0.36 ; E=-5.94 \times 10^{-5} ;$ \\
$F=-3.21 \times 10^{-6}$.
\end{tabular}

water bath heated by four recirculating heaters of $1 \mathrm{KW}$ capacity each into the water tank throughout the experiment.

We used ADM corn sweetener grade 62/43 (decanted directly from a railway tank) as our working fluid for all runs. The grade of corn syrup was chosen because of its high viscosity, chemical stability, and strongly temperature-dependent viscosity. Viscosity (figure 2) and density were measured as a function of temperature in our laboratory. Other relevant properties were provided by ADM and are listed in table 1 .

\subsection{Experimental conditions and parameters}

The initial conditions and relevant parameters of the experiments are listed in table 2. All runs started by allowing the tank fluid to cool to the lowest achievable room temperature $\left(18-20^{\circ} \mathrm{C}\right)$. Each run started at time $t=0$ when hot water was pumped 


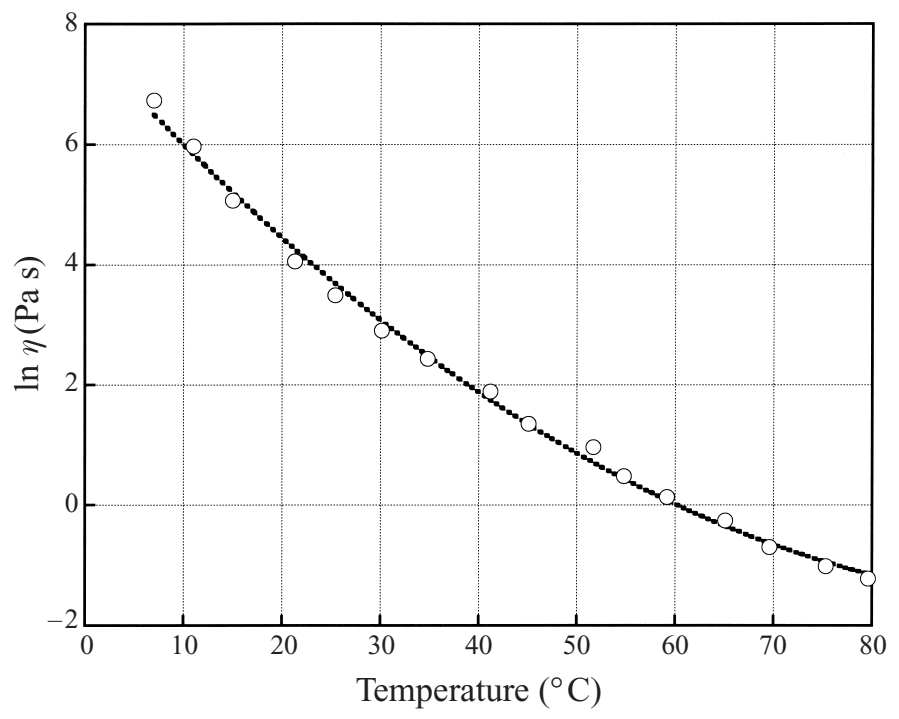

FIGURE 2. Temperature-dependence of viscosity of syrup ADM 62/43. The functional dependence is given in table 1. Viscosity was measured with a Brookfield HB digital viscometer.

\begin{tabular}{lccccccccc}
\hline No. & Duration & $T_{i}$ & $T_{f}$ & $\eta_{i}^{*}$ & $\eta_{f}^{*}$ & $R a_{i}$ & $R a_{f}$ & $P r_{i}$ & $P r_{f}$ \\
1 & $24 \mathrm{~h}$ & 18.5 & 66 & 69 & 1.6 & $1.5 \times 10^{5}$ & $3 \times 10^{7}$ & $4 \times 10^{5}$ & $5 \times 10^{3}$ \\
2 & $18 \mathrm{~h}$ & 24.4 & 72.5 & 52 & 1.4 & $1.5 \times 10^{5}$ & $7 \times 10^{7}$ & $6 \times 10^{5}$ & $3 \times 10^{3}$ \\
3 & $30 \mathrm{~h}$ & 22.9 & 68 & 44 & 1.5 & $10^{5}$ & $4 \times 10^{7}$ & $3 \times 10^{5}$ & $4 \times 10^{3}$ \\
LC1 & $12 \mathrm{~h}$ & 22.9 & 55.5 & 58.7 & 1.8 & $10^{5}$ & $4 \times 10^{6}$ & $10^{5}$ & $10^{3}$ \\
LC2 & $10 \mathrm{~h}$ & 24.8 & 52.1 & 55.4 & 3.1 & $10^{5}$ & $5 \times 10^{6}$ & $10^{5}$ & $10^{3}$
\end{tabular}

TABLE 2. Parameter and boundary conditions for all runs. $T_{i}$ and $T_{f}$ are initial and final temperature respectively; $\eta_{i}^{*}$ and $\eta_{f}^{*}$ are initial and final viscosity contrasts between bottom and well-mixed interior; $R a_{i}, P r_{i}$, initial Rayleigh and Prandtl numbers; $R a_{f}$ and $P r_{f}$, final Rayleigh and Prandtl numbers; top and bottom boundary conditions are no-slip, insulating and no-slip isothermal, respectively. Experiment LC1 had a liquid crystal temperature range of $45-60{ }^{\circ} \mathrm{C}, \mathrm{LC} 2$ of $45-50^{\circ} \mathrm{C}$.

from the water bath and continuously circulated through the water tank. The pump imposed a flow rate of $9-141 \mathrm{~min}^{-1}$ which we monitored with a shielded flowmeter.

The bottom boundary condition was essentially isothermal at any given instant in time. The rate at which water was pumped through the water tank was large enough so that as the water lost heat to the overlying fluid, the temperature drop across the hot water bath was less than $2{ }^{\circ} \mathrm{C}$. This temperature difference decreased from $2{ }^{\circ} \mathrm{C}$ (so heat flux through the convective layer decreased in time despite increasing $R a$ ) at the beginning of the experiments to less than $1{ }^{\circ} \mathrm{C}$ toward the end.

In all runs the bottom temperature increased gradually as a function of time, from the initial temperature of the water bath to the maximum desired temperature $\left(\approx 80^{\circ} \mathrm{C}\right)$. The timescale for this increase $\left(10^{-3}-10^{-4} \mathrm{~K} \mathrm{~s}^{-1}\right.$ from beginning to end in run 3 for example), however, was much larger than the transit times of thermal instabilities $\left(4 \times 10^{-3}-10^{-2} \mathrm{~K} \mathrm{~s}^{-1}\right)$, so the experiments can be viewed as being in quasi-steady state (figure 3), at least in terms of the formation and rise of plumes through the layer depth.

The total heat input rate from the hot water bath for any given run can be 


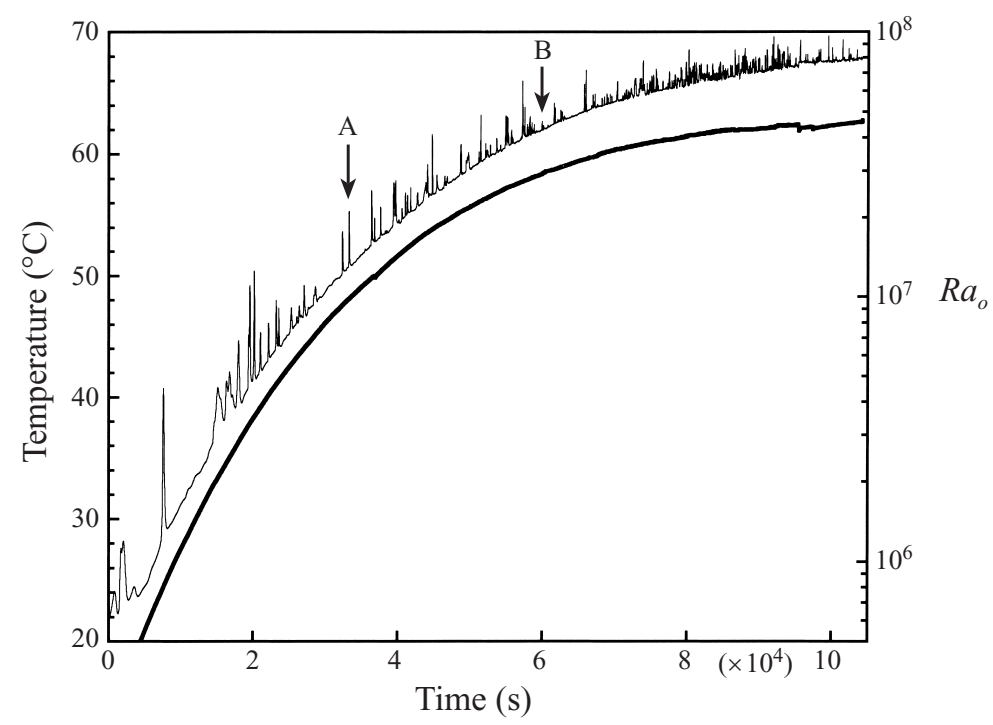

FiguRE 3. Temperature record of probe $\mathrm{E}$ for run 3. The fluctuations of temperature above background are identified as plumes and occur on much shorter time scales than the secular increase in temperature. Also shown is $R a$ as a function of time. We use the $\Delta T$ across the entire depth of the tank and the viscosity at the temperature of the well-mixed interior. Signalled with arrows and the letters $\mathrm{A}$ and $\mathrm{B}$ are the onsets of the two main mode transitions described in the text and identified in later figures.

calculated as

$$
Q_{i n}=c_{p} \Delta T \rho F
$$

where $Q_{i n}$ is the total heat input, $c_{p}$ is the specific heat of water $\left(4184 \mathrm{~J} \mathrm{~kg}^{-1} \mathrm{~K}^{-1}\right), \Delta T$ is the temperature difference between inlet and outlet water, $\rho$ is the density of water $\left(1000 \mathrm{~kg} \mathrm{~m}^{-3}\right)$, and $F$ is the flow rate $(1.5$ (Exp. 1)-2.3 (Exps. 2 and 3$\left.) \times 10^{-4} \mathrm{~m}^{3} \mathrm{~s}^{-1}\right)$. We performed three runs with different heat input rates. The total heat input rate varied between 1300 and $700 \mathrm{~W}$ for run 3, between 2200 and $800 \mathrm{~W}$ for run 2, and was roughly constant at $1000 \mathrm{~W}$ for run 1 .

The sidewalls were not insulated and a small but significant fraction of the heat was lost through the sides. Relatively little heat was conducted vertically along the sidewalls. The heat loss out and along the sidewalls was monitored by an array of thermocouples located inside and outside one of the sidewalls of the tank (figure 1). The total heat loss associated with the sidewalls is calculated as

$$
Q_{\text {sides }}=-k\left(\frac{\Delta T_{z}}{\Delta z}\right)_{y} a-k\left(\frac{\Delta T_{y}}{\Delta y}\right)_{z} A
$$

where in the first term, $k$ is the thermal conductivity of Plexiglas $\left(0.245 \mathrm{Wm}^{-1} \mathrm{~K}^{-1}\right)$, $\Delta T_{z}$ is the temperature difference between thermocouples located on the sidewall 7.5 and $22.5 \mathrm{~cm}$ from the bottom of the tank, $\Delta z$ is the difference in height above the bottom of the two thermocouples $(15 \mathrm{~cm})$, at constant horizontal position $y$, and $a$ is the cross-sectional area of the sidewall $\left(2.4 \times 10^{-2} \mathrm{~m}^{2}\right)$. In the second term $\Delta T_{y}$ is the temperature difference between the inside and outside of the tank at the same height on the sidewall, $\Delta y$ is the thickness of the wall $(2.4 \mathrm{~cm})$, and $A$ is the surface area of the sidewalls $\left(1.2 \mathrm{~m}^{2}\right)$. Taking into account the increase in temperature of the room 
through the course of the experiment, the total heat lost through the sides during the experiments was $\approx 30 \%$ of the total heat input.

In experiments with secular heating and where the fluid has a strongly temperaturedependent viscosity the Rayleigh number does not have a unique definition. We can define an effective Rayleigh number following White (1988) and Davaille \& Jaupart (1993):

$$
R a_{o}=\frac{\rho_{o} \alpha_{o} \Delta T g d^{3}}{\kappa_{o} \eta_{o}}
$$

where $\rho$ is the density, $\alpha$ is the thermal expansivity, $\Delta T$ is the temperature difference between the interior and the bottom of the tank, $g$ is the gravitational acceleration, $d$ is the depth of the tank, $\kappa$ is the thermal diffusivity of the syrup, and $\eta$ is the dynamic viscosity. The subscript $o$ indicates values taken at $T_{o}$, the smoothed background temperature measured during the experiment at mid-depth in the tank. We evaluated the effective time-dependent $R a_{o}$ (table 2) given the time-dependent values of the temperature difference and the viscosity of the interior. For the experiments described here $R a_{o}$ increased more than two orders of magnitude during the run, from about $10^{5}$ to almost $10^{8}$ (figure 3), due mainly to the effect of secular heating on the viscosity of the corn syrup.

The Prandtl number is defined as

$$
\operatorname{Pr}_{o}=\frac{\eta_{o}}{\rho_{o} \kappa_{o}}
$$

where the variables are as defined above. With this definition $\operatorname{Pr}_{o}$ was always greater than $10^{3}$, even though the viscosity of the fluid decreased throughout the experiment.

In a simple boundary layer analysis of finite-amplitude convection of unit aspect ratio, the Reynolds number is related to the Rayleigh and Prandtl numbers by

$$
R e_{o}=\frac{a R a_{o}^{2 / 3}}{P r_{o}}
$$

where $a$ is a constant less than unity. Based on the ascent times of plumes towards the end of the runs the Reynolds number in our experiments barely approaches unity. Thus, inertial effects probably remained negligible throughout the course of each individual run.

\section{Measurements: temperature and visualization}

\subsection{Thermocouple arrays}

For runs 2 and 3 the tank was equipped with an array of 16 thermocouples, some of which are depicted in figure 1 . The array was designed to measure the temperature at different heights and horizontal positions in the fluid (A-E), the heat loss through the sides ( $\mathrm{F}-\mathrm{H}$ pairs) and top (I-J) of the tank, and the temperature of the water at the inlet and outlet $(\mathrm{K}, \mathrm{L})$. One thermocouple $(\mathrm{M})$ served as calibration. All thermocouples were type $\mathrm{T}$ (copper/constantan) with exposed junctions, and an effective temperature range $\left(0-400^{\circ} \mathrm{C}\right)$ that spanned that of the experiments. The internal thermocouples were encased in stainless steel. The casings of thermocouples A and C-E were $0.16 \mathrm{~cm}$ in diameter, B's was thinner $(0.05 \mathrm{~cm})$ but never functioned properly.

All thermocouples were connected to a digital temperature board from Workbench. Thermocouples $\mathrm{A}-\mathrm{E}$ and $\mathrm{K}-\mathrm{M}$ were connected to the isothermal block of the board, the remaining thermocouples $(\mathrm{F}-\mathrm{H}$ pairs, $\mathrm{I}-\mathrm{J})$ to the non-isothermal block. Thermo- 
couples A-E and $\mathrm{K}-\mathrm{M}$ were sampled every $2 \mathrm{~s}$, all others every $5 \mathrm{~s}$. The calibration thermocouple (M) was immersed in a water bath exposed to the air. The temperature of the water bath was also measured independently with a digital thermometer. The difference in temperature was used to calibrate the temperature board prior to the experiment, and to monitor drifts in the temperature board during the experiment.

Secular drifts of the thermocouple readings $\left(\mathrm{RMS} 0.2^{\circ} \mathrm{C}\right.$, maximum $1{ }^{\circ} \mathrm{C}$ ) were observed in the course of the experiment. The characteristic time scale of these drifts (hours) was always found to be much longer than that of the dynamics. The precision (reproducibility) of thermocouple readings was always better than $0.1^{\circ} \mathrm{C}$.

\subsection{Shadowgraphs and liquid crystal films}

The vertical structure of the flow was visualized using white light shadowgraphs. For all three runs reported here two shadowgraph screens (figure 1) were set up using divergent white light sources for illumination (high-intensity projectors). The optical path to shadowgraph $\mathrm{E}$ was $2.5 \mathrm{~m}$ and that to the $\mathrm{N}$ shadowgraph was doubled to $5 \mathrm{~m}$ using a mirror $2.5 \mathrm{~m}$ away from the tank.

The shadowgraphs provided information on the vertical structure of the flow by showing variations in the index of refraction generated by temperature variations in the fluid, integrated horizontally through the tank. For the flow in these experiments, plumes were easily imaged with the shadowgraphs, and appeared as dark shadows surrounded by bright halos. The shadowgraphs during all three runs were filmed continuously with VHS video. The recordings were analysed to measure the number of plumes, the diameters of head and tails, and their ascent and residence times during the course of the experiments.

We conducted two separate runs to image the planform of convection (LC1 and LC2 in table 2). Initial and boundary conditions were similar to runs $1-3$. The bottom of the glass sheet (in contact with the syrup) was covered with nine square sheets of liquid crystal film. Liquid crystals are temperature-sensitive materials that change colour with temperature. The range of temperatures over which the colour changes from red (cold) to blue (hot) can be tailored to experimental conditions. We used thin films of liquid crystals (similar to those used for some commercial thermometers) from Hallcrest with temperature ranges $45-50^{\circ} \mathrm{C}(\mathrm{LC} 2)$ and $45-60^{\circ} \mathrm{C}$ (LC1). The liquid crystal films must be viewed at $90^{\circ}$ to the incident light to capture their true colour range. However, we filmed the developing planform continuously with a video camera suspended directly above the centre of the tank, and provided largely non-reflective illumination from two high-intensity sources with incident angles of $45^{\circ}$. The ceiling was covered with black photographer's fabric, to absorb stray light.

One difference between the planform imaging runs (LC1, LC2) and those in which the interior of the flow was measured (1-3) is that only the thin glass sheet covered the syrup in the former, and the glass was exposed directly to room air. This also provided an imperfect seal and some syrup leaked to the top of the glass, affecting the top boundary condition.

\section{Characteristics of the convective flow}

The shadowgraph and liquid crystal film videos show that flow in our experiments was always time-dependent, but that the pattern of convection was dominated by relatively long-lived, largely axisymmetric plumes. The plumes had typical mushroom shapes, i.e. large heads and thin tails, and the tails often survived for many overturn times - defined as twice the ascent time of plume heads from the bottom boundary 


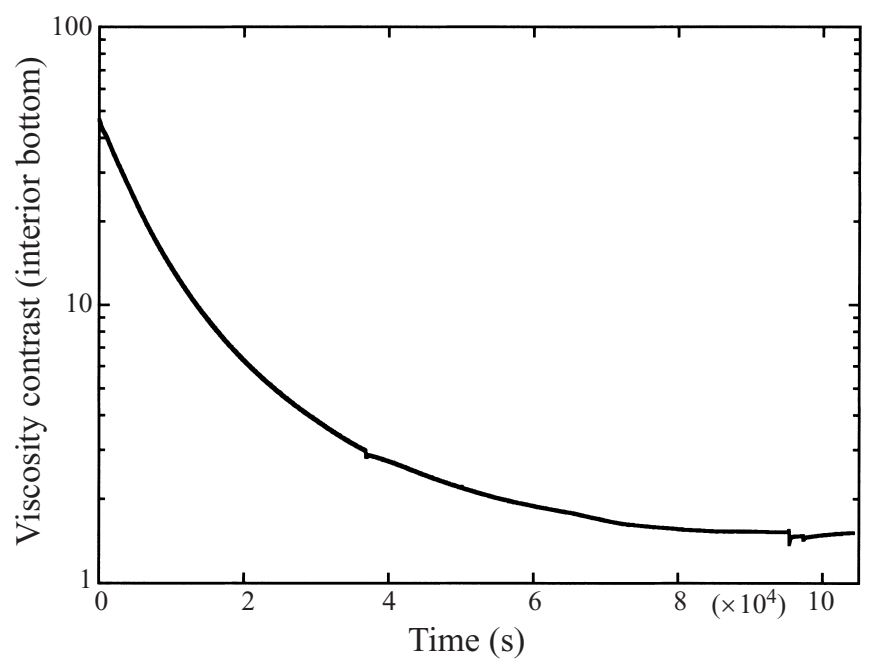

FIGURE 4. Viscosity contrast as a function of time for run 3 . The viscosity contrast is calculated by measuring the viscosity of the fluid at the bottom temperature and obtaining the viscosity at the temperature of the well-mixed interior. The contrast in viscosity decreases from about 100 at the beginning of the experiment to almost isoviscous conditions toward the end.

layer. That upwelling, cylindrical plumes are the primary structure of the flow is expected for a fluid with temperature-dependent viscosity, heated from below, and convecting at high $R a$ (White 1988; Davaille \& Jaupart 1993). The large heads and thin tails of the plumes were easily discernible in the shadowgraphs. Well-developed cold downwelling structures were not observed in these experiments because the top was a nearly insulating boundary. The dominance of plumes and the lack of welldeveloped downwellings is also apparent in the temperature time series shown in figure 3, where the oscillations above the background temperature are all one-sided for probe $\mathrm{E}$ of run 3.

\subsection{Flow evolution and bursting behaviour}

Plumes were first observed when $R a_{o}$ reached $10^{5}$ (40 times critical), between 20 and 40 minutes after the beginning of the experiment. The onset and duration of the startup phase was probably governed by the viscosity contrast across the boundary layer (Davaille \& Jaupart 1993), which decreased by a factor of 50 during the course of the experiments (figure 4). This startup phase of plume activity was characterized by the appearance of one to three very large plumes $(4-6 \mathrm{~cm}$ head diameter and $1-2 \mathrm{~cm}$ tail diameter), with typical ascent times of $\approx 25 \mathrm{~min}$. These large initial plumes were the only visible structures in the fluid for the first 50-100 minutes of the experiment.

Large plumes gave way to smaller and smaller ones as shown in the succession of shadowgraphs from run 3 in figure 5. While the size and frequency of upwelling plumes varied as a function of time, their basic structure did not change. Large-diameter heads followed by smaller-diameter tails were observed throughout the experiments. Tails stayed attached to the heads for as long as the head was visible over the full range of conditions achieved. This continuity of heads and tails indicates that 'hard thermal turbulence' does not occur in the regimes covered by our experiments (Castaing et al. 1989; Zocchi, Moses \& Libchaber 1990), which is not surprising because our flow has none of the inertial effects required for turbulence, and the Reynolds number never exceeded unity. Observations of shadowgraphs for all experiments show that 
(a) $20880 \mathrm{~s}$

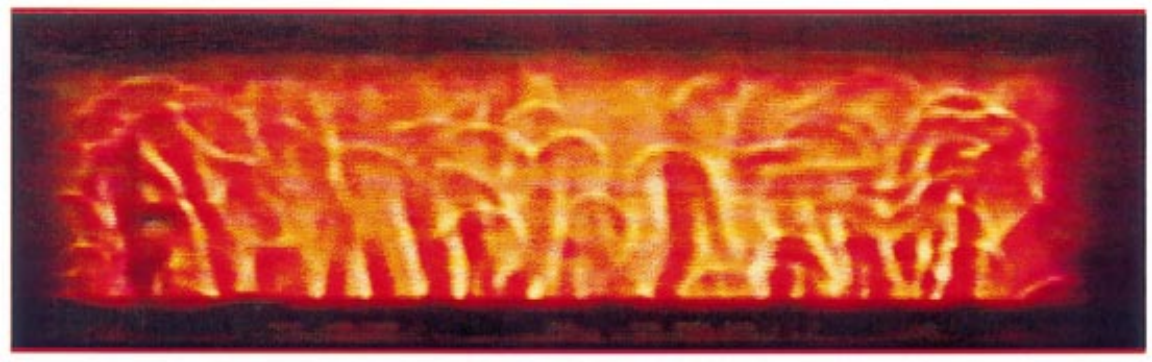

(b) $56220 \mathrm{~s}$

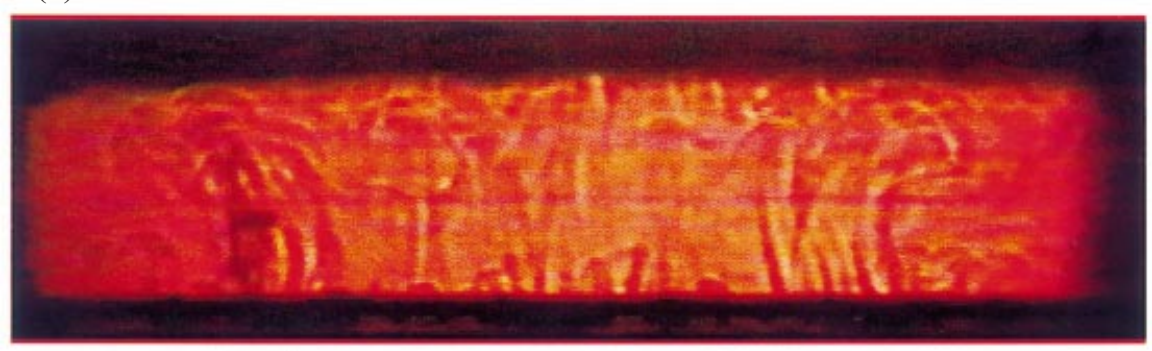

(c) $88200 \mathrm{~s}$

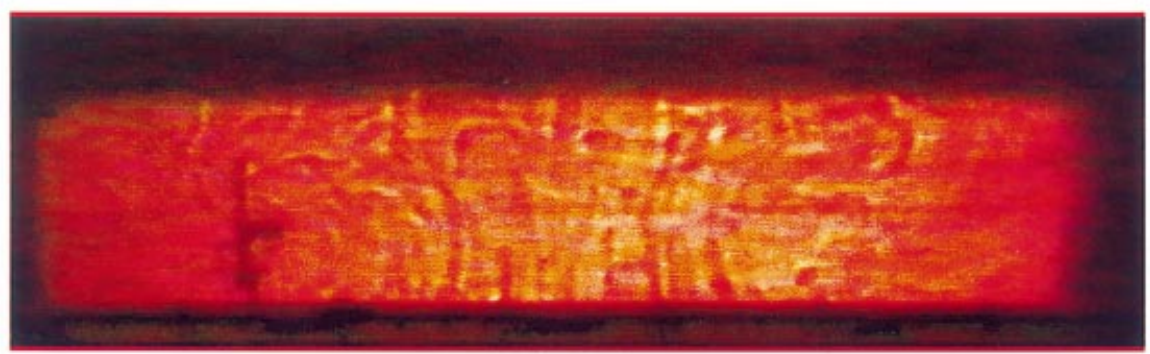

FIGURE 5. Three shadowgraphs for times 20880,56220 , and $88200 \mathrm{~s}$ after beginning of run 3. Each time corresponds to the maximum of a new episode of plume activity as seen in the frequency analysis. Note that the number and size of plumes increases from one frame to the next.

the plume tails survived for several ascent times after the heads impinged at the top surface.

In addition to a secular trend of increasing plume activity we observed a longperiod modulation of plume frequency. Long bursts of plumes, active for $6-7 \mathrm{~h}$, were followed by shorter relatively quiescent periods with a characteristic length of $1-1.5 \mathrm{~h}$. Each burst of activity also appeared to mark a dynamical transition, since plumes following a period of quiescence had noticeably reduced characteristic size and increased frequency. These bursts of plumes can be seen easily by viewing the shadowgraph videos in fast-forward, but they are also evident in the temperature series obtained from the internal thermocouples. Figure 3 shows the recordings of thermocouple E, $2 \mathrm{~cm}$ above the bottom of the tank, for run 3. Thermocouple E was particularly reliable. It was not inserted from the bottom of the tank, but rather from the side, so that it was likely to record real plume activity rather than activity 
nucleated and enhanced by heat conducted along the stainless steel casing. Although this record is from one point in the flow, three groupings by both amplitude and frequency of fluctuations are easily observed in the raw data. These three groupings correspond to visual changes in the frequency and size of plumes observed in the shadowgraph films, so they are not merely phenomena local to thermocouple probe E. The three shadowgraph video frames shown in figure 5 were chosen as times of maximum plume activity during different bursts of activity (as identified in the videos). The onset times of the active bursts in the videos correspond closely to those identified in the temperature records $(7000,34000$, and $60000 \mathrm{~s}$ after the beginning of run 3 , the last two marked by arrows in figure 3 ).

\subsubsection{Frequency of plumes}

The temperature profiles were detrended using an average profile given by the temperature record of thermocouple $\mathrm{H}$ (located at $3 / 4$ of the height of the sidewall). (A base level determined by eye would have sufficed almost as well, as seen in figure 3.) The remaining temperature anomalies represent the passage of plumes. Using the detrended temperature series we determined the frequency of anomalies and their average magnitude as a function of time. We compute the frequency of plumes with time by counting all peaks within a time window with a duration of $10^{4} \mathrm{~s}$.

The variation of plume frequency with time for probe $\mathrm{E}$ in all runs is shown in figure 6 . Frequency $\left(f^{*}\right)$ and time $\left(t^{*}\right)$ were rendered non-dimensional by choosing a time scale appropriate for this dynamical regime. At these Rayleigh numbers choosing a conductive time scale is inadequate. Instead, we chose one that represents the time for a thermal instability to traverse the layer depth at conditions averaged over the duration of each run. We express this time as $t=d / U$, where the characteristic velocity $U=\rho \alpha g \Delta T d^{2} / \eta$. As both $\Delta T$ and $\eta$ vary with time we chose the average value for each run. The frequency plots in figure 7 clearly show bursts of plume activity followed by periods of quiescence. These results are robust with respect to the size of the sliding window which we varied from $5 \times 10^{3}$ to $2 \times 10^{4} \mathrm{~s}$ with no change in the final results shown in figure 6 . It is important to note that bursting episodes occur in all three runs, as clearly seen in figure 6 . This observation implies that the bursting behaviour is not an artifact of initial conditions and secular heating rates, but rather that bursting behaviour is the preferred mode of convection in this dynamical regime (high Rayleigh numbers and subject to secular heating). In our longest and best controlled run (run 3 in figure $6 c$ ) two main transitions (excluding startup) have been identified and are easily seen in the raw data for the same run shown in figure 3. The bursting behaviour was also independently observed in the shadowgraph videos throughout the course of all three runs.

The three phases of plume activity in run 3 also had distinct characteristic temperature anomalies. At the beginning large temperature anomalies corresponding to a few (three) large plumes dominated the excursions. After this startup phase the average fluctuation decreased strongly with time and $R a_{0}$. The temperature fluctuations for this run, however, do group into three distinct phases with characteristic positive temperature spikes separated by low temperatures close to the background. The corresponding viscosity contrasts inferred from the measured temperature spikes decreased both as a result of the decreasing temperature anomaly and the smaller slope $\mathrm{d} T / \mathrm{d} \eta$ of the $\eta(T)$ curve (figure 2 ) at higher temperatures. Hence plumes correspond to spikes in $\Delta \eta$ which decreased from 4.2 to 1.2.

A large-scale convective 'wind' that deflected the plumes in their ascent was also present during the experiments (figure 5). A long-wavelength upwelling flow developed 

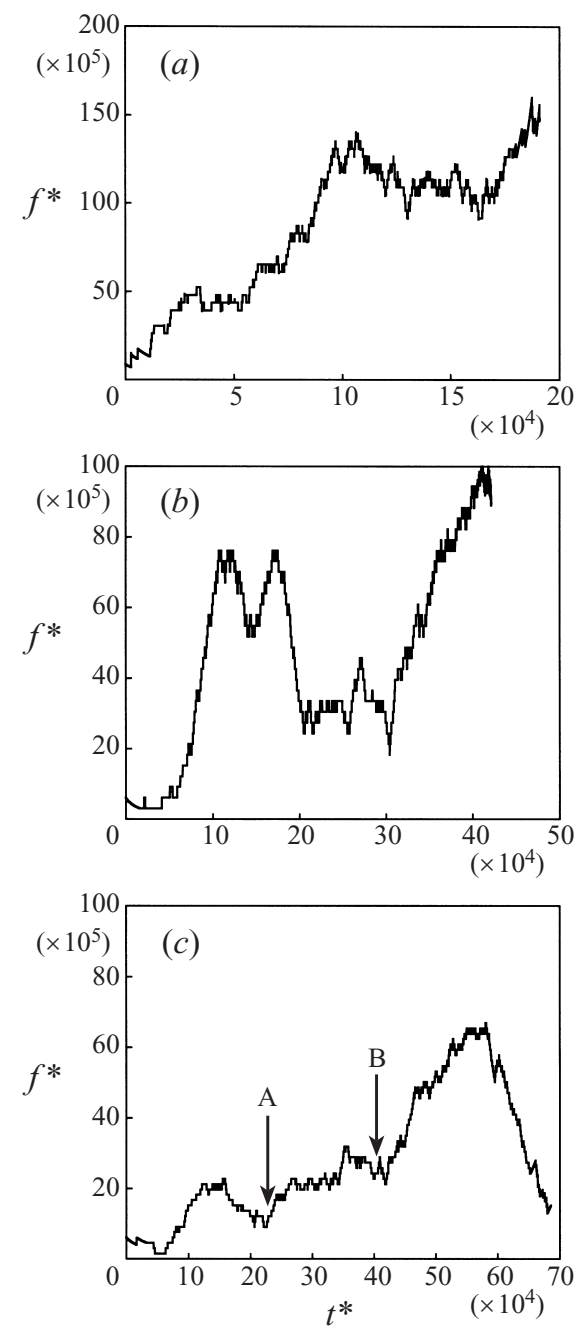

FIGURE 6. Plume frequency $\left(f^{*}=f d / U\right)$ as a function of time $\left(t^{*}=t U / d\right)$, probe E, runs $1(a), 2(b)$ and $3(c)$. Note the three periods of intense activity separated by periods of quiescence. Each period of activity is characterized by plumes of a certain frequency and size. The arrows and letters $\mathrm{A}$ and $\mathrm{B}$ in $(c)$ are the transitions between the two main phases in run 3, also seen in the raw data (figure 3) for this run. Plume counts were performed on probe E for runs 2 and 3, and on an equivalent probe for run 1. The sharp decrease in frequency at the end of the runs is not an artifact associated with the end of the time series. Edge effects were properly accounted for in our sliding window counts. The decrease in frequency is apparent on the raw data in figure 3. Plume frequency and time are scaled to a time scale corresponding to the speed of the thermal instabilities through the layer depth $t=d / U$ where $U=\rho g \alpha \Delta T d^{2} / \eta$. As most quantities vary with time we chose values corresponding to the average over the entire run.

from $\mathrm{S}$ to $\mathrm{N}$ in the tank (see sketch of the tank in figure 1) due to uneven thermal boundary conditions along the sidewalls, which were not insulated. The $\mathrm{N}$ side was closest to a window in the laboratory room and slightly cooler than the $\mathrm{S}$ side. Although the 'wind' deflected the plumes as they rose in the tank, it mainly affected those near the sidewalls, not in the centre of the tank. The effects of the large-scale wind became somewhat stronger toward the end of the experiment as 
the plumes became smaller and weaker. These interactions of plumes with much a broader overturning are relevant to the Earth's mantle, where plates subduct and drive dominant motions on scales much wider than typical upwelling spacings. We note here that if the upper surface had been cooled, the ascending plumes would have been more strongly influenced by downwelling and the somewhat cellular convection (with horizontal scales comparable to or larger than the layer depth) that would have ensued. We wished to avoid such cooling as it does not represent well the geometry of strong lithospheric plates or the effects of plate convection on mantle plumes, such as shearing by mantle flow.

\subsection{Planform of convection}

The liquid crystal sheet runs provided an interesting complement to the shadowgraph films for understanding the structure of the flow. Although these runs with liquid crystals were not of the same duration as runs 1-3 they spanned at least half the time. Because of the limited temperature range of the liquid crystal sheets the first observations of the planform could only be made $\approx 8 \mathrm{~h}$ after the experiment started, when the internal temperature was about $49^{\circ} \mathrm{C}$. The planform was then recorded for $6 \mathrm{~h}$ until the sheets were completely saturated at the blue end of the range (hot) at an internal temperature of $\approx 55^{\circ} \mathrm{C}$. The planform of convection at the upper boundary during this portion of the experiment (figure 7) was dominated by 12-14 large plumes $\approx 10 \mathrm{~cm}$ in diameter. The features with apparent cylindrical symmetry in the planform were larger than the plumes observed in the shadowgraphs, which had typical head sizes less than $2 \mathrm{~cm}$ in diameter at this stage $\left(R a \sim 10^{7}\right.$ and plume viscosity contrast $<2)$. The increase in size was due to the plume head spreading laterally as it impinged on the rigid upper boundary, while head diameters in the shadowgraph videos were measured at mid-height in the tank.

The reason for the differences between the planform and the shadowgraph observations is that two distinct plume modes of convection exist. One mode, difficult to observe in shadowgraphs, consisted of large plume heads and their feeding conduits established at an early time in the experiment, the conduits surviving for many overturn times (over $6 \mathrm{~h}$ in the planform film) and carrying hot material to the upper boundary; the other mode, more conspicuous in shadowgraphs but not apparent in the planform images, consisted of many small plumes rising along pre-existing conduits. (In the shadowgraph videos transient structures become more conspicuous than steady features.) A possible interpretation of our previous observation is that the thermal signature of early plumes is long-lived. This might lead to a stably stratified warm layer under the top boundary that warm plume fluid from the bottom boundary will tend to occupy. It is possible that in the Earth this stratification of warm fluid (perhaps the asthenosphere) might be swept away by plate convection provided there is strong enough coupling between the plates and the asthenosphere. The overall planform was dominated by large hot regions with cylindrical symmetry, surrounded by relatively linear downwellings that formed at the edges of adjacent plumes and connected in a spokelike pattern. This planform is consistent with an extrapolation of the dynamical regimes observed by White (1988) at somewhat higher viscosity contrasts and lower $R a$. The plumes seen in the liquid crystal rendering of the planform were concentrated toward the centre of the tank, while the edges were more influenced by cold downwellings. Many of the plumes did not have axisymmetric cross-sections when they first reached the top boundary, but were instead elongated in the direction of the background flow. It is important, however, to emphasize that the liquid crystal active colour temperature range only allowed a fraction of the 


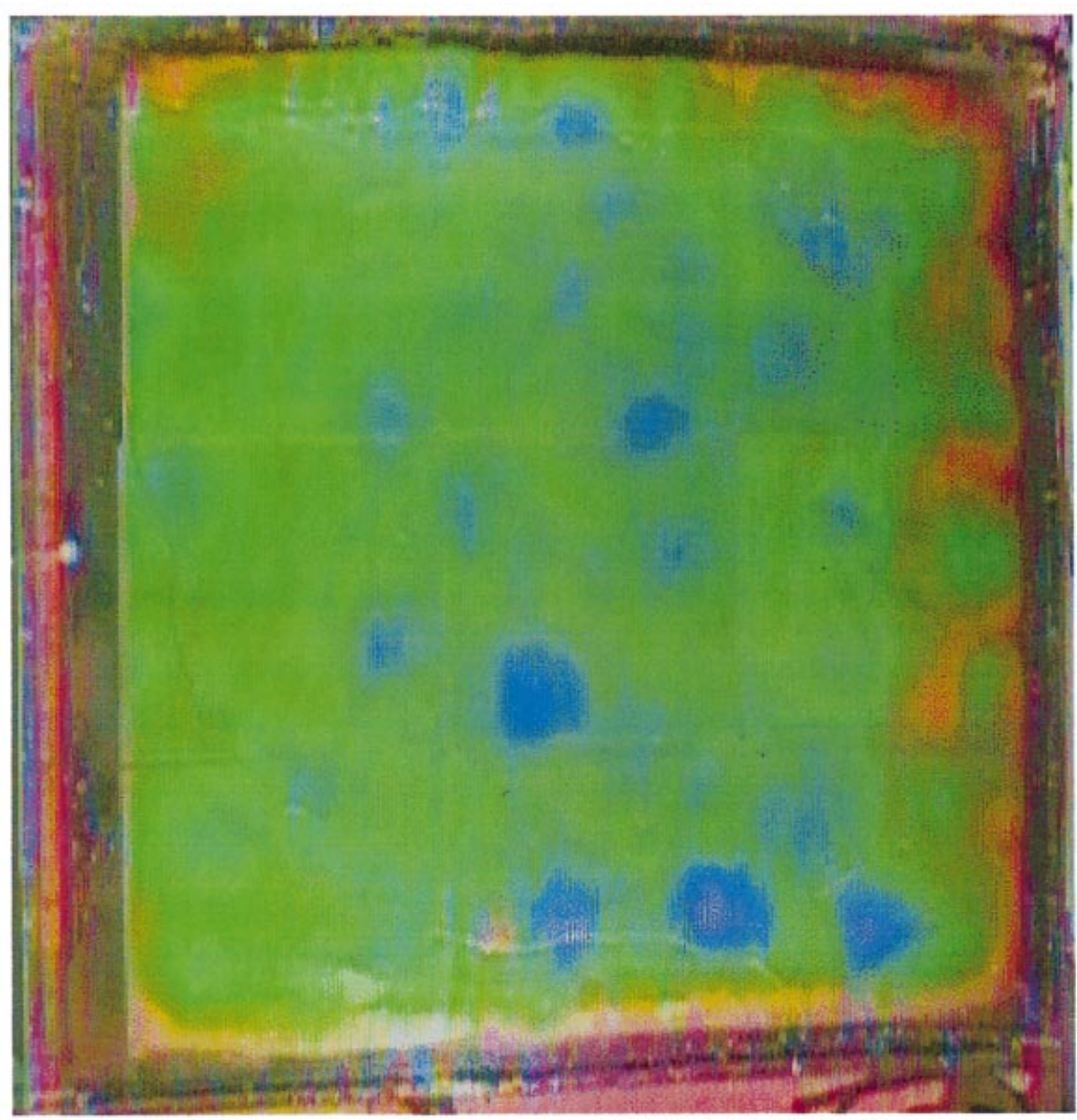

FiguRE 7. Planform of convection imaged from run LC2, $21600 \mathrm{~s}$ after the beginning of the experiment. Blue regions are hot, red regions are cold. Temperature range of liquid crystal sheets $45-50{ }^{\circ} \mathrm{C}$.

experiment to be imaged (about $6 \mathrm{~h}$ ), so that these conclusions regarding planform may not apply for the entire experiment. There was also greater heat transfer through the lid in the LC runs because the second Plexiglas sheet was removed, reducing insulation and strengthening active downwelling.

\section{Characteristics of plumes}

5.1. Time-dependence of plume size

We analysed the shadowgraph films quantitatively for the sizes of heads and tails and the plume ascent times. For consistency, we measured the plume head diameter and the tail diameter at the vertical midpoint of the tank for all times. Heads are well grown by this time and are not yet strongly influenced by the rigid top boundary. We concentrated our analysis on the interior $45 \mathrm{~cm}$ of the shadowgraph rather than the full $100 \mathrm{~cm}$ width, in order to avoid contaminating the results with edge effects. The measurements of tail diameter and head diameter were made only for plumes 


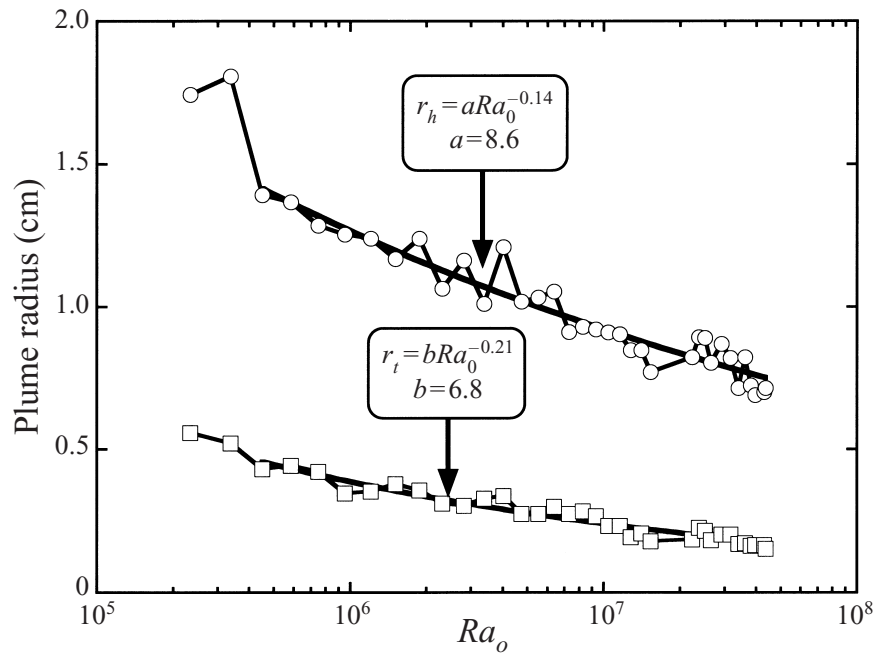

FIGURE 8. Average head and tail radii measured at mid-height in the tank as a function of $R a_{0}$ for run 3. Head diameters (open circles) and tail diameters (open squares) are averages of 14 measurements performed over 30 minutes. Shown also are fits to the data using a power law in $R a_{0}$. Fits to the data are described in the text and values of the exponent and the proportionality constant for both sets of data are shown on the figure.

that were clearly identifiable. Diameters were measured from the outer edges of the bright halo surrounding the plumes in the shadowgraphs. Head and tail diameters were measured for plumes at three distinct instants in time during a 10 minute period every half hour. The results were averaged in 10 minute bins. Toward the end of the experiments, at very large $R a_{o}$ it became increasingly difficult to make measurements: the fluid interior was well mixed, the temperature of the fluid was almost homogeneous, and variations in the index of refraction were consequently small, so that tails, heads, and ambient fluid were increasingly difficult to distinguish.

We used the measurements of head and tail diameters to characterize the sizes of plumes (figure 8). As expected, the head and tail sizes decrease with time and increasing $R a_{o}$. Both head and tail diameters are smooth functions of $R a_{o}$, although head sizes at the beginning of the experiment (first two points figure 8, each representing averages over seven separate measurements) are affected by the large initial viscosity contrast and are significantly larger than the boundary layer thickness. The head to tail radii ratio is greater than 1 (figure 9) and it increases with increasing $R a_{o}$ from about 3 to about 5 .

\subsection{Scaling analysis}

The observed decrease in the diameters of heads and tails with increasing $R a$, described above, can be understood via a simple scaling analysis. We assume that the nonconductive heat flux is dominated by plumes and that the ratio of heat transported by the plume heads, $Q_{h}$, to that transported by the plume tails, $Q_{t}$, remains the same during any given run. (This assumption may be violated, but probably not to a great extent as long as the basic character of the flow is maintained.) Thus $Q_{h} / \Delta T \propto Q_{t} / \Delta T \propto N u \propto R a_{o}^{\beta}$, where $N u$ is the Nusselt number, or dimensionless heat flow, and where the standard $N u-R a_{o}$ relationship is indicated (see, e.g. Turcotte \& Schubert 1982, p. 283) and constants such as layer depth and thermal conductivity are omitted. Heat transport by plume heads may be written as the product of a 


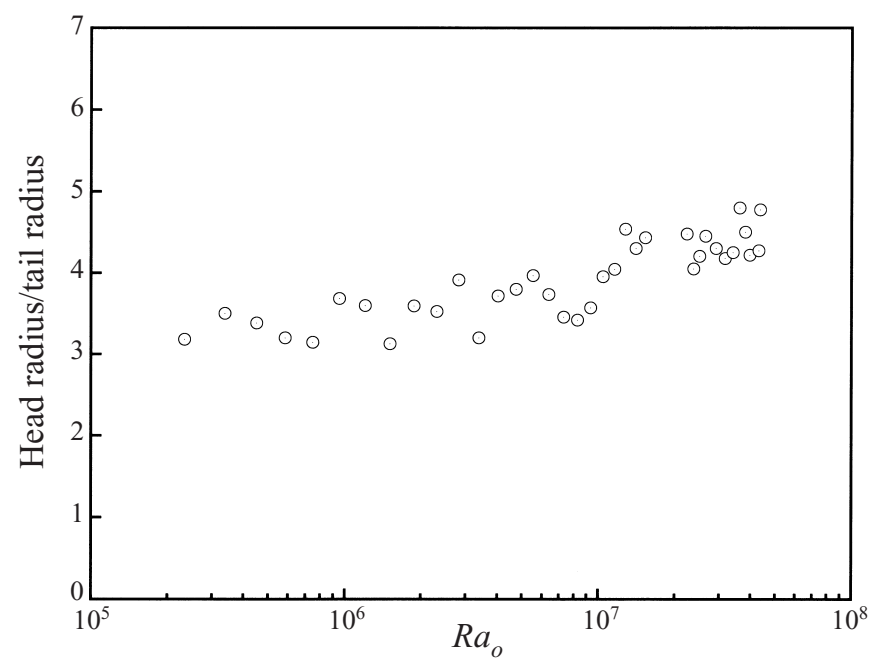

FIGURE 9. Average head-to-tail radii ratio as a function of $R a_{o}$ for run 3. Note that the ratio increases as a function of $R a_{o}$, so that the smaller plumes at larger times have relatively large heads compared to their conduits.

characteristic temperature excess, $\Delta T$, a plume head volume, and the (Stokes) rise velocity of a plume head, so that $Q_{h} \propto \Delta T\left(r_{h}\right)^{3}\left(r_{h}\right)^{2} / \eta_{o}$, where $\eta(T)$ is the viscosity of the fluid interior that characterizes $R a_{o}$, and where $r_{h}$ is a characteristic plume head radius. For the plume tails we have $Q_{t} \propto \Delta T\left(r_{t}\right)^{2}\left(r_{t}\right)^{2} / \eta_{o}$, since the cross-sectional area is the relevant dimension in this case. Since $R a_{o} \propto \Delta T / \eta_{o}$, and assuming the plume fluid has the same viscosity as the interior, the above equations imply that

$$
\begin{aligned}
& r_{h} \propto R a^{(\beta-1) / 5}, \\
& r_{t} \propto R a^{(\beta-1) / 4},
\end{aligned}
$$

where $r_{h}$ and $r_{t}$ are the radii of heads and tails respectively.

We adopt a value of 0.28 for the exponent $\beta$, a value consistent with previous experimental results at lower $R a$ with no-slip top and bottom boundaries for both constant (Rossby 1969) and temperature-dependent viscosity (Richter, Nataf \& Daly 1983). This value for $\beta$ then leads us to predict that the head and tail radii will vary as

$$
\begin{aligned}
& r_{h} \approx a R a^{-0.144}, \\
& r_{t} \approx b R a^{-0.180},
\end{aligned}
$$

where $a$ and $b$ are proportionality constants. Fitting our data on head and tail radii (figure 8) with a power law of $R a_{o}$ we find the best fitting exponent for $r_{h}$ to be -0.14 and for $r_{t}$ to be -0.21 , in reasonable agreement with our scaling analysis, especially for the plume head dependence, which is probably much better determined from the experimental measurements.

This analysis also predicts that the ratio of the head to tail radii should increase as a function of $R a$, but that the increase should be a weak function of the power of the $R a$, also in agreement with our observations (figure 9). The proportionality constants, $a$ and $b$, need not however, apply for conditions outside the $P r$ range of these experiments or the range of the temperature dependence of the viscosity. In other words, different proportionality constants may apply to the Earth's mantle. 


\section{Discussion and conclusions}

Our experiments were designed to study a fluid dynamical regime (simultaneous high $R a$ and $P r$ ) that is relevant to the generation of mantle plumes in the Earth. We investigated the formation of thermal plumes from a bottom boundary layer and examined their behaviour on moving through a wide range of Rayleigh numbers in a sequence of quasi-steady states in the same experimental run. We focused our attention on the stability of plumes, and the absolute and relative dimensions of plume heads and tails as a function of $R a$. At very high $R a$ convection is strongly time-dependent and dominated by plumes with large mushroom heads followed by thin tails - a structure maintained through the entire range of $R a$.

We found no evidence of plume heads detaching from their tails at any point during their ascent from the bottom boundary layer to the upper rigid boundary. This observation is significant because detached heads that rise as diapirs are typical of the 'hard turbulence' regime, as shown in low- $P r$, high- $R a$ laboratory experiments with liquid helium (Castaing et al. 1989; Zocchi et al. 1990; Siggia 1994). In contrast, we found that once heads impinge on the upper boundary the conduits feed the area for several overturn times. The continuity of heads and tails implies that 'hard turbulence' (which has been explained only in terms of inertial effects, specifically a critical large Reynolds number for the momentum boundary layer) does not occur for convection at these conditions.

In numerical simulations of mantle convection with geometry and conditions similar to those of our experiments, plume heads were observed to detach from the bottom boundary layer (Hansen, Yuen \& Kroening 1990; Malevsky \& Yuen 1993). On the basis of these results the authors argued (without physical justification) that the Earth's mantle is in a state of 'hard thermal turbulence' despite a vanishingly small Reynolds number. Our results are in disagreement with these numerical results, the latter of which may suffer from insufficient resolution. We expect instead that, since inertial effects are absent at very low Reynolds number (large $P r$ ), the hard turbulence regime is not relevant to either the experiments or the mantle.

The qualitative structure of the plumes remained unaltered throughout the course of the experiments, but the relative sizes of heads and tails varied significantly. Both the head and tail radii decreased with increasing Rayleigh number (figure 8). The average head radius was always much larger than the tail radius, a ratio that increased from 3 to 5 with increasing $R a_{o}$. This result is particularly interesting in the light of the fact that, over most of the experiment the conditions are nearly isoviscous. The observed ratios of head to tail radii are consistent with numerical studies of plumes in mantle convection (Farnetani \& Richards 1995) and our natural convection experiments confirm some aspects of previous models of mantle plume dynamics based on artificially generated plumes. It should be noted that the tail radius used here is the thermal radius, and this will be much larger than the radius of upwelling velocity, calculated in Griffiths \& Campbell (1990), when the viscosity decreases with increasing temperature. A simple scaling analysis for the isoviscous case roughly predicts the power-law dependence on $R a_{o}$ of the observed head and tail radii, and the increase in the head-to-tail ratio. The head size decreases with time owing primarily to the decreasing ambient viscosity.

In scaling our results to the Earth's mantle we can use either the ratio of the average head size to the height of the tank or the observed head to tail ratio. We obtain estimates of plume head diameters in the middle of the mantle ranging from 150 to $500 \mathrm{~km}$. However, we expect that the head-to-tail ratio (and hence the scaled 
head diameters) will increase with viscosity contrast (e.g. Griffiths \& Campbell 1990; Farnetani \& Richards 1995).

The convection planform exhibited long-lived upwelling plumes, while the shadowgraphs showed more transient, smaller axisymmetric structures. This suggests the existence of two types of plume-like structures in the Earth's mantle. The first, corresponding to the large long-lived features observed in the planform runs, manifests itself as hotspot tracks. Melting of the large head material generates large flood basalt provinces on continents and ocean crust (Morgan 1981; Richards et al. 1989; Griffiths \& Campbell 1990). The second, associated with the smaller plumes seen in the shadowgraphs, might give rise to isolated seamounts, or 'lesser' hotspots, which might be deflected and destroyed by the large-scale mantle circulation associated with plate motions. We must however, add three caveats: (i) the bottom boundary of the mantle is free-slip rather than no-slip (as in our experiments), which might cause plumes to be smaller in the mantle and encourage merging and relative motion among plume conduits; (ii) the bottom thermal boundary layer thickness of the Earth's mantle is probably modulated by large-scale flow due to plate motions and subduction, which we have not simulated in our experiments; (iii) the insulating lid of our experiments might also contribute to the longevity of the hot patches observed in the planform experiments, as there is little horizontal motion in the top boundary layer to remove them.

Finally, a surprising result was the bursting behaviour and apparent mode transitions in plume activity. We observed two large transitions characterized by changes in plume frequency and size (figure 6). We do not understand this phenomenon or why the frequency and size of plumes do not vary smoothly and monotonically with time. This behaviour suggests that the convecting system cannot be described as being in secular equilibrium. In our experiments the interior viscosity and the forcing temperature difference decrease with time, and it is possible that the bursting and mode transitions are due to the inability of the system to keep up with this imposed secular forcing. Perhaps the thermal boundary layer thickness does not remain in equilibrium with the slowly changing interior viscosity and forcing temperature difference. One possibility is that as $R a_{o}$ increases, the existing boundary layer (now of greater than equilibrium thickness) is more unstable and continues to throw off large plume heads, hence losing a flux greater than that provided at the boundary. The boundary layer thereby cools and becomes more stable. After a period of conductive warming with fewer new plumes, activity begins again with a thinner boundary layer appropriate to the new larger $R a_{o}$. Plumes then continue to heat the interior.

Abrupt changes in the nature of convection in a system with secular forcing is potentially significant for convection in the Earth and other terrestrial planets, even though the sign of the forcing is opposite to that of our experiments. Whereas our experiments are characterized by secular heating the terrestrial planets have probably cooled by hundreds of degrees during the 4.5 billion years of the solar system existence. The apparent mode transitions that we observe occur during the first two thirds of our experiment where viscosity contrasts are large and most comparable to the Earth's interior. Moreover the ratio of plume rise time to cooling time is similar in the Earth and our experiments. For the Earth we have a ratio of $1: 100$ (assuming a plume rise time of 30 million years and a cooling time of 3 billion years), while for our experiments we have a plume rise time of about $200 \mathrm{~s}$ and a cooling time of $20000 \mathrm{~s}$ (the $1 /$ e-folding time of the viscosity). The burst in plume activity in the experiments occurred on a time scale of $\approx 17000 \mathrm{~s}$. We note that for the Earth, formation of the continental crust appears to be episodic (Sastil 1960; McCulloch \& Bennett 1994), 
and might be related to large magmatic events triggered by bursts of mantle plume activity, though in this case the Rayleigh number has probably been decreasing rather than increasing with time, due to surface cooling.

We recall that our concern has been with plume convection arising from the heated bottom boundary layer, under the assumption that there is a partial decoupling of the dynamics of this mode of convection in the mantle from convection associated with distributed internal heating (due to radioactivity), surface cooling and associated rigid lithospheric plates. These modes cannot be completely decoupled and the plateconvection can influence plumes from the bottom through a large-scale 'wind' or by driving a slow secular cooling of the mantle. These will be interesting interactions to investigate. However, the present case of forcing from the heated base alone seems to us the simplest system relevant for understanding plume convection from the base of the mantle. Thus our somewhat serendipitous discovery regarding bursting and mode transitions warrants further investigation, both experimental and numerical, in order to understand the occurrence and characteristics of such phenomena. One would like to know if analogous behaviour occurs with secular cooling, a question that could be addressed by numerical modeling.

The authors thank the technical staff (Dave Smith and John Donovan) of the Department of Geology and Geophysics at the University of California, Berkeley, for their assistance in building the tank. We wish to thank the Archer Daniels Midland corporation for donating several hundred gallons of syrup for these experiments.

\section{REFERENCES}

Busse, F. H. \& Whitehead, J. A. 1971 Instabilities of convection rolls in a high Prandtl number fluid. J. Fluid Mech. 47, 305-320.

Castaing, B., Gunaratne, G., Heslot, F., Kadanoff, L., Libchaber, A., Thomae, S., Wu, X. Z., ZALESKI, S. \& ZANetTI, G. 1989 Scaling of hard thermal turbulence in Rayleigh-Benard convection. J. Fluid Mech. 204, 1-30.

Davaille, A. \& Jaupart, C. 1993 Transient high-Rayleigh-number thermal convection with large viscosity variations. J. Fluid Mech. 253, 141-166.

Davies, G. F. \& Richards, M. A. 1992 Mantle convection. J. Geol. 49, 459-486.

Farnetani, C. G. \& Richards, M. A. 1995 Thermal entrainment and melting in mantle plumes. Earth Planet. Sci. Lett. 136, 251-267.

Feighner, M. A. \& Richards, M. A. 1995 The fluid dynamics of plume-ridge and plume-plate interactions - An experimental investigation. Earth Planet. Sci. Lett. 129, 171-182.

Goldstein, R. J., Chiang, H. D. \& See, D. L. 1990 High-Rayleigh-number convection in a horizontal enclosure. J. Fluid Mech. 213, 111-126.

GRIFFITHS, R. W. 1986 Thermals in extremely viscous fluids, including the effects of temperaturedependent viscosity. J. Fluid Mech. 166, 115-138.

Griffiths, R. W. \& CAMPBell, I. H. 1990 Stirring and structure in mantle starting plumes. Earth Planet. Sci. Lett. 99, 66-78.

Griffiths, R. W. \& Richards, M. A. 1989 The adjustment of mantle plumes to changes in plate motion. Geophys. Res. Lett. 16, 437-440.

Hansen, U., Yuen, D. A. \& Kroening, S. E. 1990 Transition to hard turbulence in thermal convection at infinite Prandtl number. Phys. Fluids A 2, 2157-2163.

Haskell, N. A. 1935 The motion of a viscous fluid under a surface load, I. Physics 6, 265-269.

JellineK, A. M., Kerr, R. C. \& Griffiths, R. W. 1999 Mixing and compositional layering produced by natural thermal convection. Part 1 . The experiments, and their application to the Earth's core and mantle. J. Geophys. Res. 104, 7183-7201.

Malevsky, A. V. \& Yuen, D. A. 1993 Plume structures in the hard-turbulent regime of threedimensional infinite Prandtl number convection. Geophys. Res. Lett. 20, 383-386. 
McCulloch, M. T. \& BennetT, V. C. 1994 Progressive growth of the earth's continental crust and depleted mantle. Geochim. Cosmochim. Acta 58, 4717-4738.

Morgan, W. J. 1972 Plate motions and deep mantle convection. Mem. Geol. Soc. Am. 132, 7-22.

Morgan, W. J. 1981 Hotspot tracks and the opening of the Atlantic and Indian Oceans. In The Sea vol. 7, pp. 443-487. Wiley-Interscience.

Olson, P., Schubert, G., Anderson, C. \& Goldman, P. 1988 Plume formation and lithosphere erosion: A comparison of laboratory and numerical experiments. J. Geophys. Res. 93, 15065 15084.

Olson, P. \& Singer, H. 1985 Creeping plumes. J. Fluid Mech. 58, 511-531.

Ragnarsson, R., Ford, J. L., Santangelo, C. D. \& Bodenschatz, E. 1996 Rifts in spreading wax layers. Phys. Rev. Lett. 76, 3456-3459.

Renne, P. R., Zhang, Z. C., Richards, M. A., Black, M. T. \& others 1995 Synchrony and causal relations between Permian-Triassic boundary crises and Siberian flood volcanism. Science 269, $1413-1416$.

Richards, M. A., Duncan, R. A. \& Courtillot, V. E. 1989 Flood basalts and hot-spot tracks-plume heads and tails. Science 246, 103-107.

Richards, M. A. \& Griffiths, R. W. 1988 Deflection of plumes by mantle shear flow: experimental results and simple theory. Geophys. J. Intl 94, 367-376.

Richards, M. A., Hager, B. H. \& Sleep, N. H. 1988 Dynamically supported geoid highs over hotspots: Observation and theory. J. Geophys. Res. 93, 7690-7708.

Richards, M. A., Jones, D. L., Duncan, R. A. \& DePaolo, D. J. 1991 A mantle plume initiation model for the Wrangellia flood basalt and other oceanic plateaus. Science 254, 263-267.

Richter, F. M., NATAF, H.-C. \& Daly, S. F. 1983 Heat transfer and horizontally averaged temperature of convection with large viscosity variations. J. Fluid Mech. 129, 173-192.

Rossby, H. T. 1969 A study of Benard convection with and without rotation. J. Fluid Mech. 36, 309-336.

SAStiL, G. 1960 The distribution of mineral dates in time and space. Am. J. Sci. 258, 1-35.

SigGia, E. D. 1994 High Rayleigh number convection. Ann. Rev. Fluid Mech. 26, 137-168.

Steinberger, B. \& O'Connell, R. J. 1998 Advection of plumes in mantle flow: implications for hotspot motion, mantle viscosity and plume distribution. Geophys. J. Intl 132, 412-434.

Turcotte, D. L. \& Schubert, G. 1982 Geodynamics: Applications of continuum physics to geological problems. John Wiley.

Weeraratne, D. \& Manga, M. 1998 Transitions in the style of mantle convection at high Rayleigh numbers. Earth Planet. Sci. Lett. 160, 563-568.

Weinstein, S. A. \& Olson, P. 1990 Planforms in thermal convection with internal heat sources at large Rayleigh and Prandtl numbers. Geophys. Res. Lett. 17, 239-242.

White, D. B. 1988 The planforms and onset of convection with a temperature-dependent viscosity. J. Fluid Mech. 191, 247-286.

Whitehead, J. A. \& Luther, D. S. 1975 Dynamics of laboratory diapir and plume models. J. Geophys. Res. 80, 705-717.

Wilson, J. T. 1963 A possible origin of the Hawaiian Islands. Can. J. Phys. 41, 863-870.

Zocchi, G., Moses, E. \& Libchaber, A. 1990 Coherent structures in turbulent convection, an experimental study. Physica A 166, 387-407. 